\title{
Adapting global shared socio-economic pathways for national scenarios in Japan
}

\author{
He Chen $^{1}\left(\mathbb{D} \cdot\right.$ Keisuke Matsuhashi $^{1} \cdot$ Kiyoshi Takahashi $^{1} \cdot$ Shinichiro Fujimori $^{2,3} \cdot$ Keita Honjo $^{4} \cdot$ Kei Gomi $^{1}$
}

Received: 26 September 2019 / Accepted: 30 December 2019 / Published online: 22 January 2020

(c) The Author(s) 2020

\begin{abstract}
Shared socio-economic pathways (SSPs) are alternative global development scenarios focused on the mitigation of and adaptation to climate change. However, global SSPs would need revised versions for regional or local assessment, which is the so-called extended version, because global narratives may lack region-specific important drivers, national policy perspectives, and unification of data for each nation. Thus, it is necessary to construct scenarios that can be used for governments in response to the SSPs to reflect national and sub-national unique situations. This study presents national SSP scenarios, specifically focusing on Japan (hereafter, Japan SSPs), as well as a process for developing scenarios that qualitatively links to global SSPs. We document the descriptions of drivers and basic narratives of Japan SSPs coherent with global SSPs, based on workshops conducted by local researchers and governments. Moreover, we provide a common data set of population and GDP using the national scale. Japan SSPs emphasized population trends different from global SSPs and influencing factors, citizen participation, industrial development resulting from economic change, distribution, and inequality of sub-national population, among others. We selected data sets from existing population projections that have been widely used by Japanese researchers; the data show that the population and GDP of Japan SSPs are expected to be about 20-25\% less than global SSPs by 2100 .
\end{abstract}

Keywords Shared socioeconomic pathways $\cdot$ Climate change $\cdot$ Special report on emissions scenarios $\cdot$ Intergovernmental panel on climate change $\cdot$ Narratives

Handled by Rajarshi DasGupta, Institute for Global

Environmental Strategies, Japan.

Electronic supplementary material The online version of this article (https://doi.org/10.1007/s11625-019-00780-y) contains supplementary material, which is available to authorized users.

He Chen

chen.he@nies.go.jp

Keisuke Matsuhashi

matuhasi@nies.go.jp

Kiyoshi Takahashi

ktakaha@nies.go.jp

Shinichiro Fujimori

sfujimori@athehost.env.kyoto-u.ac.jp

Keita Honjo

honjo.keita@pref.saitama.lg.jp

Kei Gomi

gomi.kei@nies.go.jp

\section{Introduction}

Global warming countermeasures demand potential pathways. Scenario analysis has emerged as a key tool in studies of climate change mitigation and adaptation (Pedde et al. 2019). Major research initiatives related to climate change, including research on climate mitigation measures using

1 National Institute for Environmental Studies, 16-2 Onagawa, Tsukuba, Ibaraki 305-8506, Japan

2 Kyoto University, Yoshida Honmachi, Sakyo-ku, Kyoto City, Kyoto 606-8501, Japan

3 International Institute for Applied Systems Analysis, Schlossplatz-1, 2361 Laxenburg, Austria

4 Center for Environmental Science in Saitama, Kamitanadare 914, Kazo City, Saitama Prefecture 347-0115, Japan 
integrated assessment models, simulations with climate models, evaluating the impacts and adaptations of climate change, and assessment of global socioeconomic scenarios development, have been carried out vigorously (Riahi et al. 2017; IPCC 2000; van Vuuren et al. 2011). Among these efforts, the initial representative effort is the Special Report on Emissions Scenarios (hereinafter referred to as "SRES"), which the intergovernmental panel on climate change (IPCC) announced in 2000 (IPCC 2000). However, the process for constructing a scenario to replace SRES was decided by research communities at the IPCC expert meeting held in Noordwijkerhout, The Netherlands, in 2007, and a so-called new scenario process began (IPCC 2007). In the new scenario development process, the Representative Concentration Pathways (van Vuuren et al. 2011) was first developed. Then, climate models (earth system models) generated future climate scenarios based on the RCPs under CMIP5 (Coupled Model Intercomparison Project) exercise (Taylor et al. 2012); moreover, shared socio-economic pathways (SSPs) have been simultaneously developed (Riahi et al. 2017).

The SSPs are socio-economic development pathways in the twenty-first century that incorporate narratives and quantitative information. Quantitative information mainly drives future climate change forces such as greenhouse gas and air pollution emissions as well as land use (e.g., demography, macroeconomy, and energy). SSPs consist of five alternative scenarios characterized by sustainable development, regional rivalry, inequality, fossil-fueled development, and middle-of-the-road development (Riahi et al. 2017). Narratives and quantifications of SSP1-5 span a wide range of different futures broadly representative of the current literature, and enable their subsequent use and development in new assessments and research projects (Riahi et al. 2017). The narratives of the SSPs (O'Neill et al. 2017) were developed using expert teams that together designed the storylines and ensured their internal consistency. For each SSP, population (KC and Lutz 2017), urbanization projection (Jiang and O'Neill 2017), land use (Popp et al. 2017), and three different economic perspectives (Crespo Cuaresma 2017; Dellink et al. 2017; Leimbach et al. 2017) were developed. Six integrated assessment models (IAMs) were used for the quantification of the SSP scenarios (Calvin et al. 2017; Fricko et al. 2017; Fujimori et al. 2017; Kriegler et al. 2017; van Vuuren et al. 2017). After the publication of the SSPs, there are wide range of applications from global human system to the nature and ecosystems assessment (Chaudhary and Mooers 2018; Rogelj et al. 2018; Kim et al. 2018; Zhang et al. 2017; Kok et al. 2016).

While the SSPs have a great advantage that can be used by global models with same assumptions, it has already addressed that revised versions would be needed for the regional assessment, which is the so-called extended version
(O'Neill et al. 2014). There are multiple reasons for this: First, global narratives may fail to incorporate regional specific important drivers. As an example of Japan, an aging society, obtaining labor force from abroad would be highly policy relevant nowadays; moreover, these elements can have multiple possibilities that are not explicitly described in the global scenarios. Second, global scenarios do not always reflect national policy perspectives that can be major drivers for a particular region's development. For example, some countries may have their own energy perspectives that would primarily determine near-term energy-related emissions; however, they can hardly be adopted in the global scenarios. Third, global scenarios are intensively checked in terms of global or continental regional aggregation levels to have a consistent view in the global context, but country data are not always investigated; however, their consistency with the historical statistics for each nation warrants regular checks. Thus, it is necessary to construct new socio-economic scenarios that can be used for the assessment of climate change impacts, adaptation, and mitigation measures by national and sub-national governments in response to the SSPs, to reflect local unique situations.

Few studies have built on the SSP architecture and applied it at the national scale (Alfieri et al. 2015; Carey 2014; König et al. 2015; Palazzo et al. 2017; Steininger et al. 2016), or the sub-national scale (Absar and Preston 2015; Nilsson et al. 2017; Kok et al. 2019; Pedde et al. 2019; Zandersen et al. 2019).

Nilsson et al. (2017) combined participatory bottom-up and top-down methodology with results from the Barents region in Russian. Local actors voted for the most relevant drivers, and the respective narrative elements were recorded by means of extensive notes from group and plenary discussions. The result shows that the focus question (or the main diver by regional actors) did not include the word 'climate.' Thus, further work would be required to produce more attempts and combinations for quantifying some drivers (such as GDP and population). Absar and Preston (2015) used a top-down method to create storyline elements for factors, actors, and sectors at the global, national, and subnational levels, provided there was a structured process for addressing the challenge of the scale discordance and the information gap. Nevertheless, the quantification of the GDP and the population applied county-level scaling factors to the national population and GDP estimates within the IIASA database. However, it lacked a reflection of the characteristics in different regions; thus, it is difficult to be widely used by local governments and related researchers. Palazzo et al. (2017) developed a new set of scenarios and framework for linking scenarios across levels to characterize the connection between West African scenarios and global SSPs beginning with the characteristic of 'comparable.' However, discussions about the differences and characteristics within regions 
are lacking. Kok et al. (2019) present a set of four European SSPs until 2100 and a novel method to develop qualitative stories for Europe equivalent to the global SSPs, and Pedde et al. (2019) explore systematically future society's ability to achieve the $1.5^{\circ} \mathrm{C}$ target. Zandersen et al. (2019) present regional narratives in the Baltic Sea region, focus on agriculture, fisheries and other drivers that represent major pressures on the Baltic Sea. This study demonstrated the possibilities that regional conditions and sectoral activity levels may deviate from the global SSPs. Therefore, national and sub-national SSPs need to reflect global trends, as well as the unique development direction and policy choices that may reinforce or may be different with the global SSPs.

On the other hand, the greenhouse gas reduction amount was not achieved for the 2 degrees target by the Paris Agreement. Countries, including Japan, are required to further increase the reduction target in the future. Since climate change is an issue that needs to be jointly addressed worldwide, mitigation measures in Japan are more comparable by internationally recognized scenarios, such as SSP, when considering the long-term path, to significantly reduce greenhouse gas emissions. Moreover, as the effects of climate change differ depending on the national and local climatic and socioeconomic conditions, it is important to proceed with adaptation measures in accordance with the circumstances of the country or region. Therefore, the impact assessment made by the Japanese version of SSP is needed while considering adaptation measures according to the Japanese government's adaptation strategies.

This study presents a new process for narratives of scenario development that qualitatively links to global SSPs and basic quantitative information of Japan. Moreover, downscale narratives are constructed for the use of governments in response to the global SSPs, to reflect unique national and sub-national situations. Thus, a set of scenarios was created that principally focuses on regional challenges; the set was created to be coherent with global SSPs, thereby allowing for a global context of the scenarios.

\section{Framework of Japan SSPs}

The process of developing the Japanese SSPs is driven by the general purpose of global SSPs, and the regional characteristics of Japan. A global scenario framework has been developed and aims to be relevant for local adaptation planning and projecting future emissions. However, it provides boundary conditions and constraints on local and sectoral scenarios but cannot be downscaled in a deterministic way as with the climate system (Ebi et al. 2014).

The schematic illustration of the main steps in developing the Japan SSPs is shown in Fig. 1. Japan SSPs and subnational Japan SSPs were developed based on global SSPs (top-down method), workshops, and existing Japan projections (bottom-up method). The output of this study is shown in bold face; the future studies to be developed are presented in dotted boxes (in italics). Global SSPs include 4 main parts (Fig. 1): the narratives, socioeconomic scenario drivers (basic SSP elements), baseline and mitigation scenarios, and databases (Riahi et al. 2017). The narratives of global SSP include 5 basic narratives and 6 categories of element (demographics, human development, economy and lifestyle, policies and institutions, technology and environment, and natural resources) (O’Neill et al. 2017) to provide

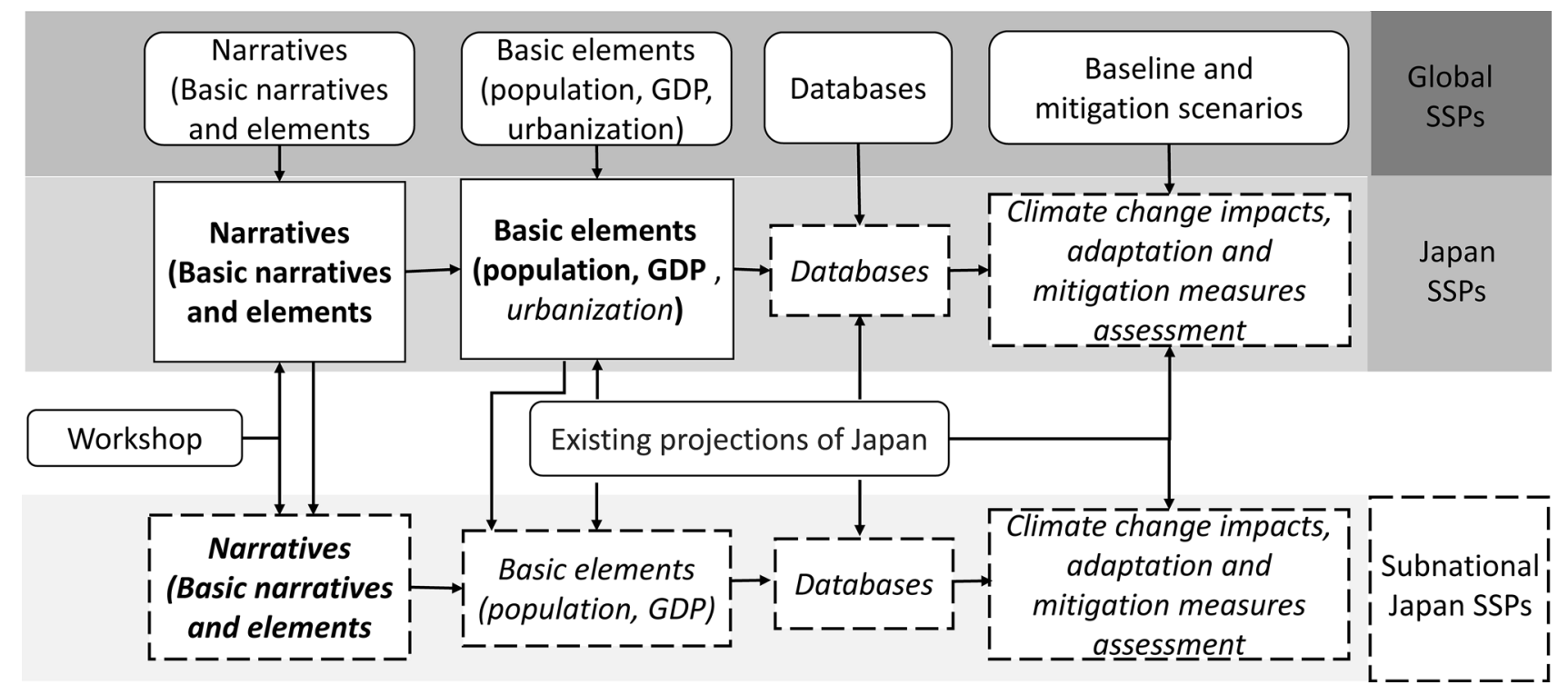

Fig. 1 Schematic illustration of the main steps in developing the Japan SSPs 
broad descriptions of future conditions that are relevant for both mitigation strategies and potential adaptation measures. Japan SSPs specifically focus on both qualitative (narratives) and quantitative elements (basic elements, database), which need to be presented in sets to facilitate widespread use.

First, the basic narratives were developed in terms of text description and extensions of the narratives were developed in terms of tables, to describe the qualitative terms, the Japan narratives and the range of scenario assumptions.

Second, for each Japan SSP, projections with long-term time horizons (2100) of the quantitative elements (population, urbanization, and GDP) are important, as this study focused on establishing platforms and processes for collaborative work of integrated assessment and impact/adaptation/ vulnerability researchers on integrated scenarios (Kriegler et al. 2012). For urbanization, there remained questions regarding the degree of detail necessary within each element and whether additional categories of element (for example: industry, input-output, etc.) are required.

Finally, both the narratives and the associated projections of socio-economic drivers were elaborated using a range of integrated assessment models, to derive quantitative projections of energy, land use, and emissions associated with the Japan SSPs. The next steps of the Japan SSPs will comprise development of the downscaling method for rendering landuse scenarios in grid units with high spatial resolution (Pixel size: $1 \mathrm{~km}^{2}$ ), and quantification information of basic indicators (population, GDP, land use, etc.) as well as indicators specific to each sector such as agriculture, water resources, and human health. Future researches are also focusing on developing sub-national SSPs that can be used for climate change impact assessment of prefectures or municipalities. As parts of series study, a Japanese study group is estimating future economy and population for 6 prefectures in the Kanto region, by considering the way of working and living. Saitama Prefecture, which has been actively tackling climate change countermeasures, conducted, as a model, an economic assessment of climate risk based on quantified information by sub-national scale, and will compile the results keeping in the mind the long-term climate adaptation plan.

The ultimate goal of the Japan SSPs is used for climate risk assessment and adaptation measures in Japan and local governments, providing a research community engaged in climate change impact assessment of Japan's socio-economic scenarios associated with global SSPs. Nevertheless, in this study, we do not include the IAM quantification or subnational adaptation here and are limited to the first and parts of the second phase.

\section{Methodology}

First, based on the framework of narratives of global SSPs, the narratives of Japan SSPs were developed by drawing on experts' opinion in workshops, to identify key determinants of these challenges that are important for Japan, both incorporating and different from the global narratives. The workshop was organised by NIES (National Institute for Environmental Studies), and gathered 15 scientists, and policymakers over 2 days. Participants' specialties include ecology, economics, climate change, biopolymorphism, sustainable society, and policy advice. Three groups of experts (5-6 people each group) participated in the discussion, ensuring adequate discussion on theinterpretation of each element.

In the workshop, all the participants identified the drivers affecting the future of Japan that should be considered in the Japan SSP. Drivers affecting Japan's future society include artificial intelligence utilization, health, genomic technological advancement, fully automated driving, and drivers related to basic income, education, and governance, as well as dematerialization and diversity.

Therefore, to further deepen the discussion, the groups were divided into three, and each group proceeded to identify drivers.

In addition to the content proposed, drivers such as the way of infrastructure development and the direction of industrial policy are also proposed. After reviewing the drivers presented, the study specifically selected divers related to mitigation and adaptation to climate change, identify drivers with similar content, and narrow down the particularly important divers. Thus, to narrow the subsequent discussion down to key issues, the participants vote for the most important drivers by writing their name behind the drivers. Then, participants clustered drivers into numbers of distinct categories and analyze whether the drivers belong to the challenge for adaptation, challenge for mitigation, or both.

The participants described how the challenge for adaptation or mitigation might interact regionally. Thus, the participants described the context provided by SSP1-SSP5 O'Neill except SSP2. SSP2 was not discussed because the main purpose of workshop is to use set boundary condition that would "maximally span the mitigation and adaptation space" (Carlsen et al. 2016).

Then, based on the workshop and global SSP, text descriptions of the narratives were developed in terms of sketch, and the similarities and differences with global SSPs were marked. The extensions of the narratives were developed to show the range of assumptions about individual elements of the pathways, by describing in qualitative terms the elements, and scenario assumptions. Elements that are considered important in the workshops were added to the tables. 
Finally, the population and GDP are calculated as basic data base to support climate risk assessment and adaptation measures in Japan and sub-national scale's extensions. For the population, global SSPs used the average OECD population which is much higher than the average birth rate in Japan. To better utilize SSPs in Japan, this study used existing population projection data as future population. GDP projections were quantified based on population of Japan projections and GDP per capital of global SSP projections.

\section{Results}

Key drivers were documented based on the votes for the most important drivers. The descriptions of the basic narratives were organized as sketch and tables.

\section{Key drivers of Japan SSPs}

The "voting" results are presented in Table 1. The results of Japan SSPs drivers that contribute to high or low challenges to mitigation and adaptation are presented in Fig. 2.

Easy challenges for adaptation results in creative education include high levels of immigrant acceptance, continuous domestic innovation, favorable conditions for the younger generations, improved international relations, and the promotion of traditional cultures. Hard challenges for adaptation lead to overseas innovation, polarization by education, immigrant discrimination, trade barriers, the collapse of the social security system, and youth outflow. Easy challenges for mitigation lead to a high information society, competitive low-carbon energy technologies, productivity gains, diffusion of shared economic, and block-chain technology improvement. Hard challenges for mitigation cause mass production consumption,

Table 1 Key drivers in the workshop

\begin{tabular}{|c|c|c|}
\hline Challenges for mitigation & Challenges for adaptation & Challenges both for mitigation and adaptation \\
\hline $\begin{array}{l}\text { Dependent on import or not (food, energy), } \\
\text { (votes: } 2 \text { ) }\end{array}$ & $\begin{array}{l}\text { Will societies and communities react with } \\
\text { determination, or with resignation, (votes: } 5 \text { ) }\end{array}$ & $\begin{array}{l}\text { Population change, population distribution, } \\
\text { (votes: } 4 \text { ) }\end{array}$ \\
\hline $\begin{array}{l}\text { Protect the current industry or invest in new } \\
\text { industrial technology, (votes: } 2 \text { ) }\end{array}$ & $\begin{array}{l}\text { Household redistribution (average life expec- } \\
\text { tancy voting weight?), (votes: 4) }\end{array}$ & How AI works, (votes:3) \\
\hline Economic growth or not, (votes: 1) & $\begin{array}{l}\text { Governance (equal opportunity/centralized), } \\
\text { (votes: } 2 \text { ) } \\
\text { Polarization or not, (votes: } 2 \text { ) } \\
\text { Diversity or not, (votes: } 2 \text { ) } \\
\text { Will conscious determination be efficiency or } \\
\text { not, (votes: } 1 \text { ) } \\
\text { Will education be creative or, not, (votes:1) }\end{array}$ & $\begin{array}{l}\text { Genetic diagnosis, medical be better or not, } \\
\text { (votes: } 1 \text { ) }\end{array}$ \\
\hline
\end{tabular}

(a)

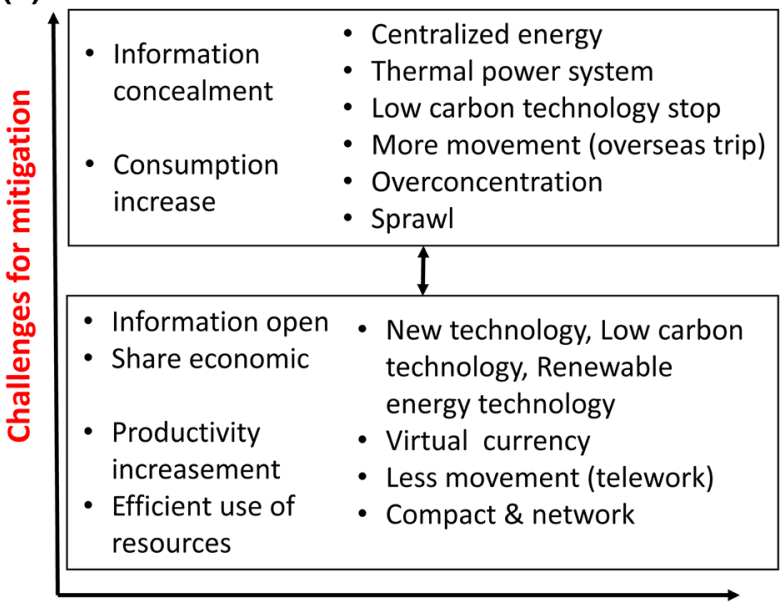

(b)

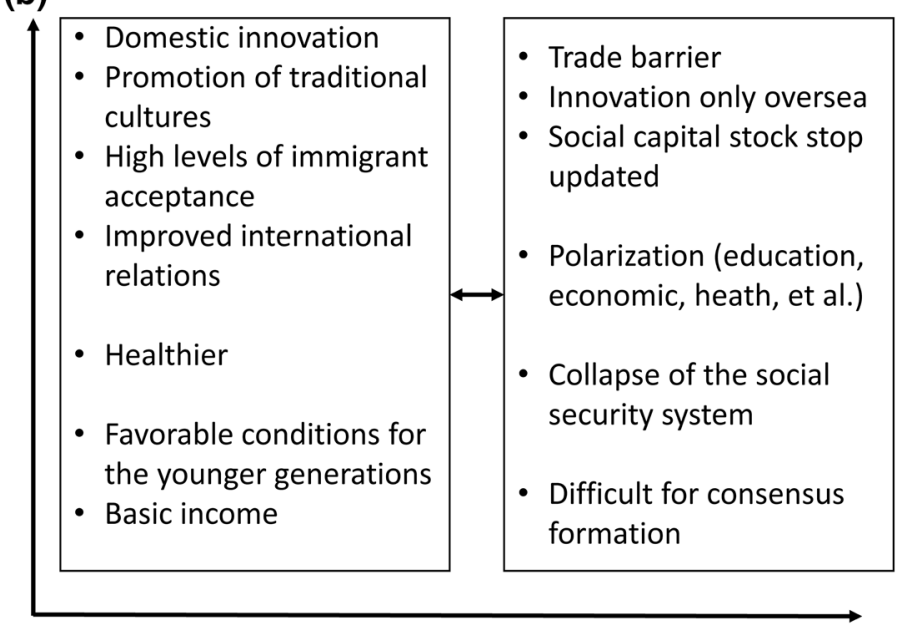

Challenges for adaptation

Fig. 2 A summary of Japan SSPs drivers that contribute to high or low challenges to mitigation (a) and adaptation (b) 
non-transparent information, emphasis on economic development over the protection of the environment, urban sprawl, and insufficient investment in infrastructure. Furthermore, individual SSP elements and their increase or decrease were discussed in the workshop.

\section{Basic narratives of Japan SSPs}

Based on the discussion in the workshops, we documented the narratives in the form of correcting the sketch of the global SSP. Specifically, we extended the description applicable to regional scale, and modified the description of the population to fit Japan. Descriptions on industry, employment, migration, responsiveness, and diversity were added as key elements affecting Japan's scenario. Differences in the basic narratives between Japan SSPs and global SSPs, and additional descriptions are shown in Table 2. A sketch of Japan SSPs is included in Supplementary Materials: Appen$\operatorname{dix}$ A.

The characteristics of Japan SSPs are as follows.

\section{Japan SSP1}

The central features of SSP1 are to achieve development goals, and increase environmental awareness in societies; for this goal to succeed, policy changes which are driven by changing attitudes would be needed (O'Neill et al. 2017).

Based on discussions in the workshop, population concentration in metropolitan areas and downtown areas has been relaxed, and the proportion of people living in local and suburban bases (compact + network) is relatively increasing. For more details of the population, refer to chapter 3.3.

Local entities actively utilize new technologies, considering characteristics such as the terrain of the area, weather conditions, and resources. Such entities develop special businesses such as tourism, agriculture, forestry and fisheries, and energy business. Thus, economic self-reliance is improving. Moreover, abandoned areas of cultivation have decreased, food self-sufficiency rate has improved, and appropriate management of forests and utilization of forest resources are progressing. Furthermore, local resources and its appeal have been rediscovered; tourism and the sixth industrialization of agriculture, as well as the forestry and fishery industries, have progressed, thereby enriching the region.

The development and utilization of new technologies are actively carried out, the utilization of AI and robot technology has also progressed, and many labor-intensive jobs are being replaced. Human beings are playing a higher valueadded work; therefore, an education orientation towards creative human resources development is carried out. Hence, women's advancement in society advances.
In Japan SSP1, childcare environment investments accelerate the fertility rates, and therefore, the population decline is relatively relaxed. In addition, although Japanese are highly educated, excessive living pressure and childcare environment are considered as the factors affecting birth rate. While in global SSP, educational attainment is mentioned as a critical aspect, and educational and health investments result in relatively low population levels in SSP1 (O'Neill et al. 2017).

Japan SSP1 leads to progress in political participation of citizens; actors make social decisions during repeated dia$\log$ s with each other. As a result, mutual understanding is widely spread, even for principals with different opinions and characteristics, and a tolerant society that recognizes diversity is being constructed. Since trust among different entities in society is fostered, societal decision-making is smoothly carried out. The social trend that acknowledges diverse values widely penetrates corporations, and the transparency of decision-making within the company also increases.

Consumption is oriented toward low material growth and lower resource and energy intensity in global SSP1 (O'Neill et al. 2017); while in Japan SSP1, consumption is oriented toward sharing service with low material growth and high value-added service industry development. Although the narratives of global SSP1 emphasized cooperation and collaboration of national and international organizations and institutions (O'Neill et al. 2017), the workshop focused on the local issues and discussed more about the citizen participation.

Similar to global SSP1, Japan SSP1 presents low challenges to mitigation and adaptation.

\section{Japan SSP2}

Global SSP2 implies a development pathway that is consistent with typical patterns of historical experience, observed over the past century (O'Neill et al. 2017).

Global population growth is moderate and levels off in the second half of the century as a consequence of completion of the demographic transition in global SSP2 (O'Neill et al. 2017). However, the Japanese population is inevitably affected by a decline in birth rates and an aging population, which will be reduced, following the past trends. Investing in the environment for raising children can alleviate the decline in population, but not increase the birth rate to stabilize the population. Economies of most countries and regions are politically stable in the global SSP2, while the agricultural sector will be late but the internationalization of the market will proceed in Japan SSP2 according to the past trends.

Similar to global SSP2, Japan SSP2 faces moderate challenges to mitigation and adaptation. 


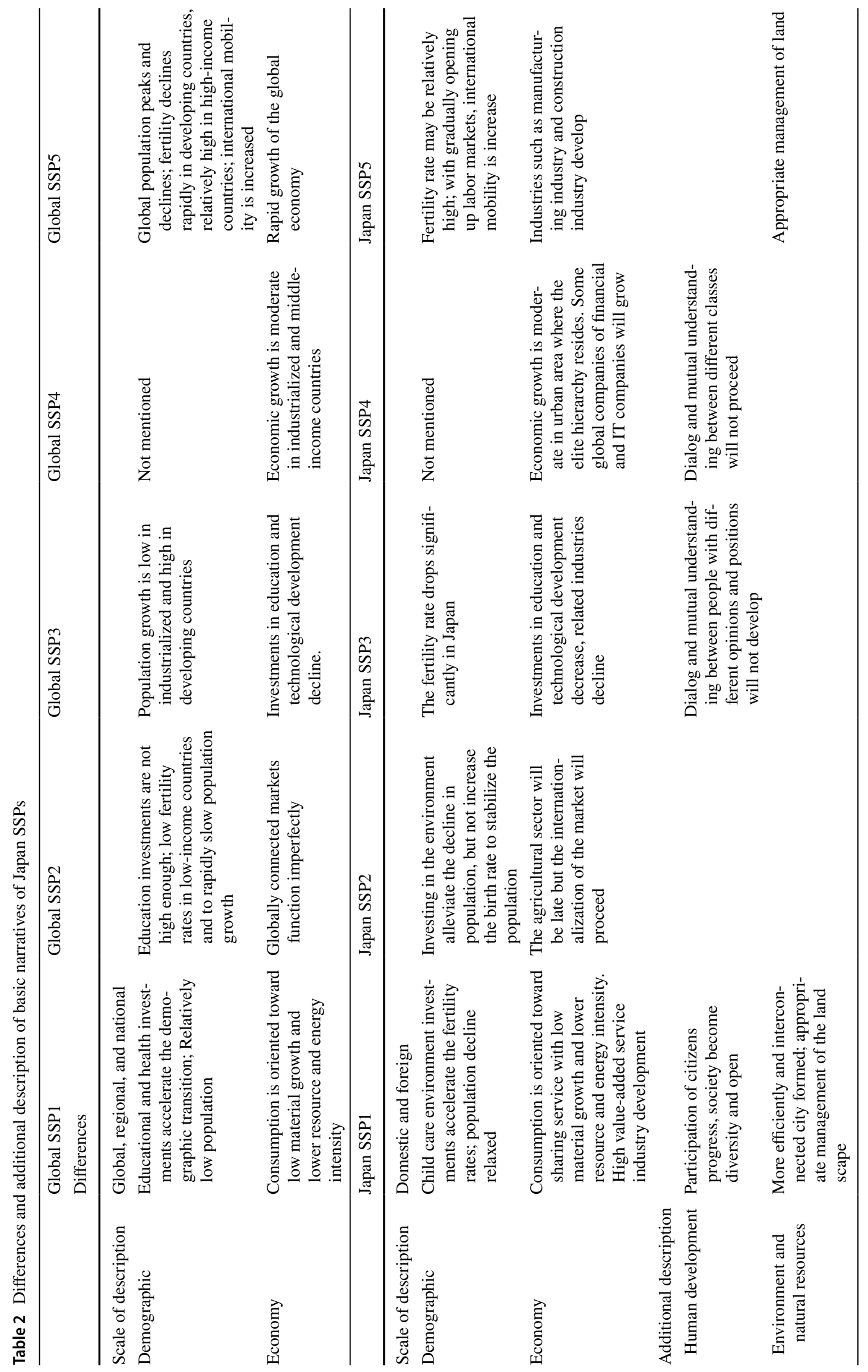




\section{Japan SSP3}

The theme of global SSPs is international fragmentation and a world characterized by regional rivalry (O'Neill et al. 2017); the theme reflects in the description of Japan SSP3: social division.

Based on discussion in the workshop, migration is concentrated in one direction as moving into the city advances. However, in rural areas, the population continue to decline due to the migration to cities, and many villages and communities have disappeared. Due to the declining population and industrial competitiveness in rural areas, abandoned areas of cultivation and the devastation of forests will continue to increase.

The economic aspect is stagnant in Japan SSP, since the introduction of innovative technologies and product development are not sufficiently advanced, and the competitiveness has declined. Moreover, the budget deficit has also expanded, and investment in people such as pensions, medical expenses, education, childbirth, and child-rearing support is decreasing. There is a negative chain where the development of human resources does not progress due to a decrease in investment in people; technology development is delayed, and the competitiveness declines. Thus, the economy stagnates.

Japan SSP3 focuses on citizens with different identities. Based on the workshop, the political participation of citizens does not advance, and some layers substantially monopolize policy decisions in Japan SSP3. Dialog and mutual understanding among people with different opinions and characteristics are hardly carried out; society has been divided, making it intolerant toward others.

Population growth is low in industrialized countries in global SSP3. However, the population level is not only low, but also significantly reduced in Japan in Japan SSP3, as the fertility rate in Japan is already the lowest worldwide. While economic development is slow around the world in global SSP3, international competitiveness is especially declining in Japan in Japan SSP3.

Japan SSP3 presents high challenges to mitigation and adaptation.

\section{Japan SSP4}

Global SSP4 emphasizes on both across- and within-country inequality, which is assumed to arise from a number of factors discussed in the inequality literature, including skillbiased technology development and unequal investments in education.

Economic growth is moderate in urban areas where the elite hierarchy resides, while other areas face financial difficulties, in many cases, struggling to provide people with infrastructure and services to maintain living standards.
Existing industries continue to occupy an important position, and the financial and IT industries continue to develop. High-income groups will earn further income by utilizing advanced technologies such as AI and robots. Given these technologies, however, the poor will lose their jobs, and the disparity will expand before it is fixed.

Based on more extended discussion on the workshop, the division between the central area where the highincome group resides and the surrounding area where the poor live is strengthened within the metropolitan area, even though the concentration in one direction will progress further as people move to the metropolitan area. In the former, infrastructure development is substantial, and safe living is guaranteed. In the latter, however, in place of adequate infrastructure are slums. The rural areas continue to decline as huge numbers of people continue to migrate to cities, and new industries are not created.

Inequality in opportunities for employment and political participation will increase, and the associated disparities will widen. Opinions of vulnerable people are hardly reflected in institutions and policies; this is a vicious cycle that promotes indifference at the whim of public decision-making.

While the discussion focused on inequality across and within countries in global SSP4, Japan SSP4 describes more differences between classes, cities, and districts.

Japan SSP4 presents low challenges to mitigation and high challenges to adaptation.

\section{Japan SSP5}

Global SSP5 foresees accelerated globalization, rapid development of developing countries, and success of emerging economies (O'Neill et al. 2017).

In Japan SSP5, fertility levels are relatively high due to optimistic economic outlooks. Labor markets gradually opened up, international mobility is increased, and foreign workers greatly increase. Development and utilization of new technologies will progress. The movement of people from overseas is also active, and the development of technology is shared globally through the exchange of highly educated personnel.

The manufacturing and construction industries will lead the economy as an export industry. People are mainly responsible for research and development, as well as system management by enhancing the redistribution system against the backdrop of economic growth and human capital investment.

Based on more extended discussion on the workshop, the tendency for population and capital to concentrate more strongly in cities will increase. While, traditional agriculture, forestry, and fisheries industries in rural areas 
decline following the mass migration, mechanized agriculture, forestry and fishery industries, such as plant factories utilizing new technologies, develop and spread.

Japan SSP5 presents high challenges to mitigation and low challenges to adaptation.

\section{Elements}

The narratives of global SSP include 6 categories of elements (demographics, human development, economy and lifestyle, policies and institutions, technology and environment and natural resources) (O'Neill et al. 2017). Based on the discussion of each Japan SSP, Table 3 summarizes assumptions about key elements of the different narratives with the global elements. Adjusted assumptions are shown in green background, and added elements are shown in blue background, same assumptions area shown as $\bigcirc$.

Regarding the demographics, we also explored the population distribution in addition to mortality and fertility, as well as the specific increase and decrease of population in different areas of the city. The fertility, mortality, and migration are presented at the left of the average OECD elements in global SSPs. The elements in Japan SSPs have several different expressions based on the workshop as population distribution is supposed to revitalize regional bases. There remains the concentration of networks in Japan SSP 1; there are disparities, slums of the poor, and the decline of villages and communities in Japan SSP3; there is the concentration in urban centers and sprawl in other areas in Japan SSP4; and there is the population concentration in the Tokyo area, as well as a partial sprawl in Japan SSP5. Total population increase is shown in the right of the table.

The economic growth is the same as that of the average OECD. For energy technological change, technological development of photovoltaic power generation and storage batteries, and cost reduction, the introduction of a legal system will occur in Japan SSP1. High nuclear Power Generation will occur in Japan SSP4. Furthermore, considering the employment and industrial composition discussed in the local context, AI and robots will do simple labor in Japan SSP1, and simple labor will increase in Japan SSP3 to Japan SSP5.

The continuation of the landscape, forest, and agricultural context is similar to the global SSPs. The infrastructure was especially discussed because of the great risk in the challenge of adaptation and mitigation involved in the future infrastructure for the young and aging society in Japan. The utilization of green infrastructure, such as erosion control forests and windbreak forests, is considered to be produced in Japan SSP 1 and developed in the Japan SSP 5. The infrastructure has not been fully implemented in Japan SSP 3. In Japan SSP 4, the infrastructures are fulfilling for highincome groups. For the poor, however, there are slums.

\section{Quantification of the population}

As stated in 2.2, to better utilize SSPs in Japan, existing and widely used demographic models or data should be used as the population data.

In the IIASA calculations, the average OECD population used the average OECD birth rate (1.75, United Nations 2011). However, this birth rate is much higher than the average birth rate in Japan (1.44 NIPSSR 2017). The direct use of IIASA data does not reflect the characteristics of the region and is likely to cause greater errors, leading to irreparable errors in policy guidance. Moreover, if we use the future population (2010-2100) in Japan by National Institute of Population and Social security Research (NIPSSR), which use the same definitions as IIASA, we will find that the gap between the various Japan SSPs is very small, and it is impossible to reach the guiding significance of the future prediction.

Therefore, the NIPSSR database (the data set that conforms to the future Japan SSPs population release law) will be selected as the basic data. NIPSSR is an institute that provides demographic data and initiates the "Population Projection for Japan" projection, which project the overall size and age-gender breakdown of the future population. This projection, based on information from the Census, vital statistics, and various national representative surveys, is widely used by the national and local governments and in various fields in Japan.

First, the results of the population projections were confirmed using company research estimates (SSP Data 2018) that fit the fertility and mortality descriptions of global SSPs. The results are presented in Table 4.

When we selected the firm's estimates that corresponded to the assumptions (high, medium, low) for the fertility and mortality rate of global SSPs 1-5 (Fig. 3, SSP1-SSP5), the consideration of immigration was not enough, and there was not much difference in the population among the scenarios. Therefore, to reflect the trend of population decline in Japan on a global scale from global SSPs $1-5$, corrections were made by multiplying the ratio by a fixed ratio, which is between the global SSP2 and medium fertility and mortality by NIPSSR. The results were set as the procedure to select one from conditional estimates of NIPSSR, and shown in Fig. 4, SSP1'-SSP5'.

The population projections medium fertility and mortality by NIPSSR were set as the population projection of Japan SSP2. The lines of SSP2' and Japan SSP2 are coincident. Since the range of the population considered by the difference in the mortality rate is extremely small, the mortality rate was unified at the center of the company estimates. Since the assumed birth rate in the global SSP is a high figure for Japan, the case of high fertility, which will be $18 \%$ (73 million) in 2100, was selected as the Japan SSP1. 


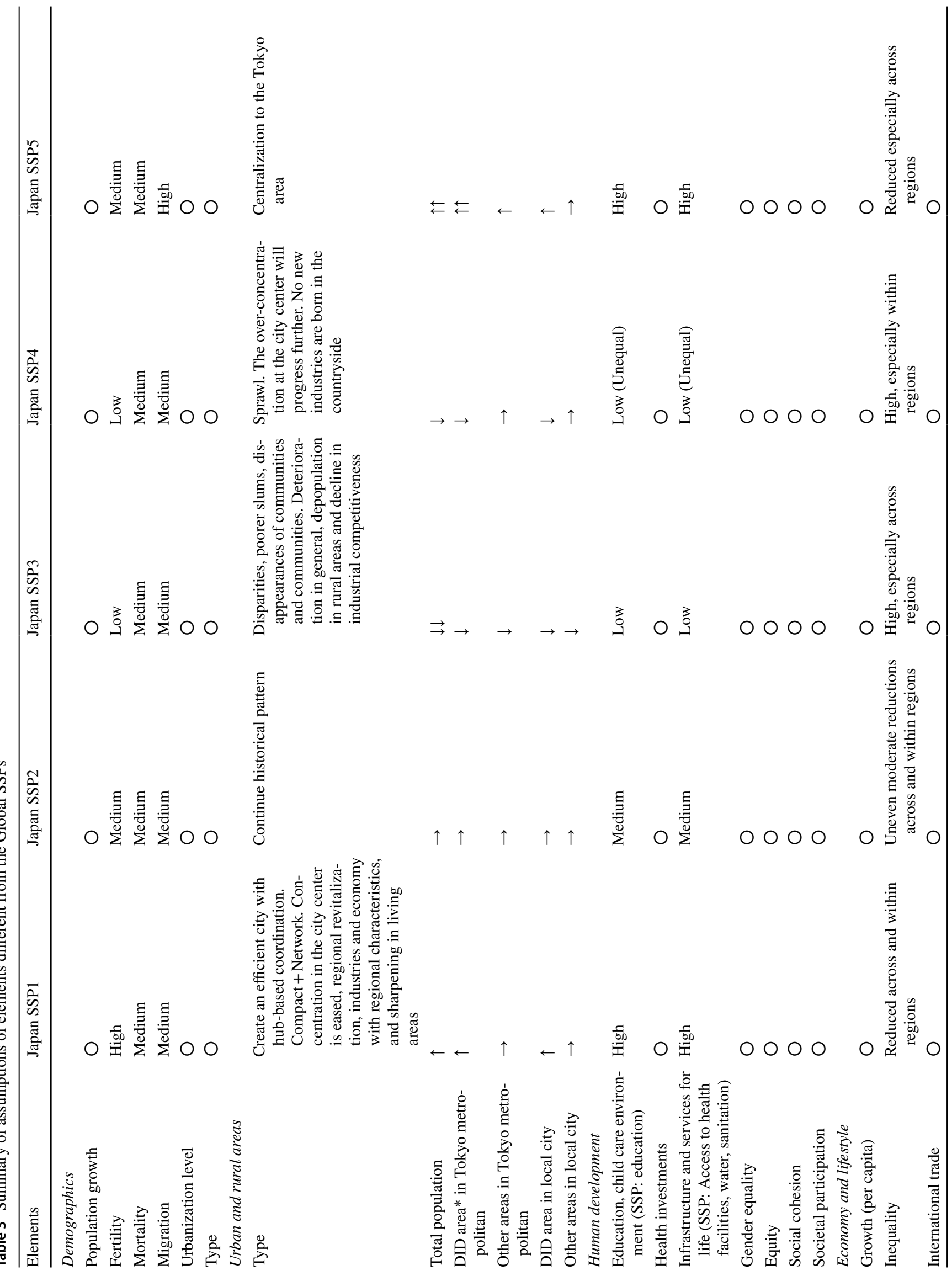




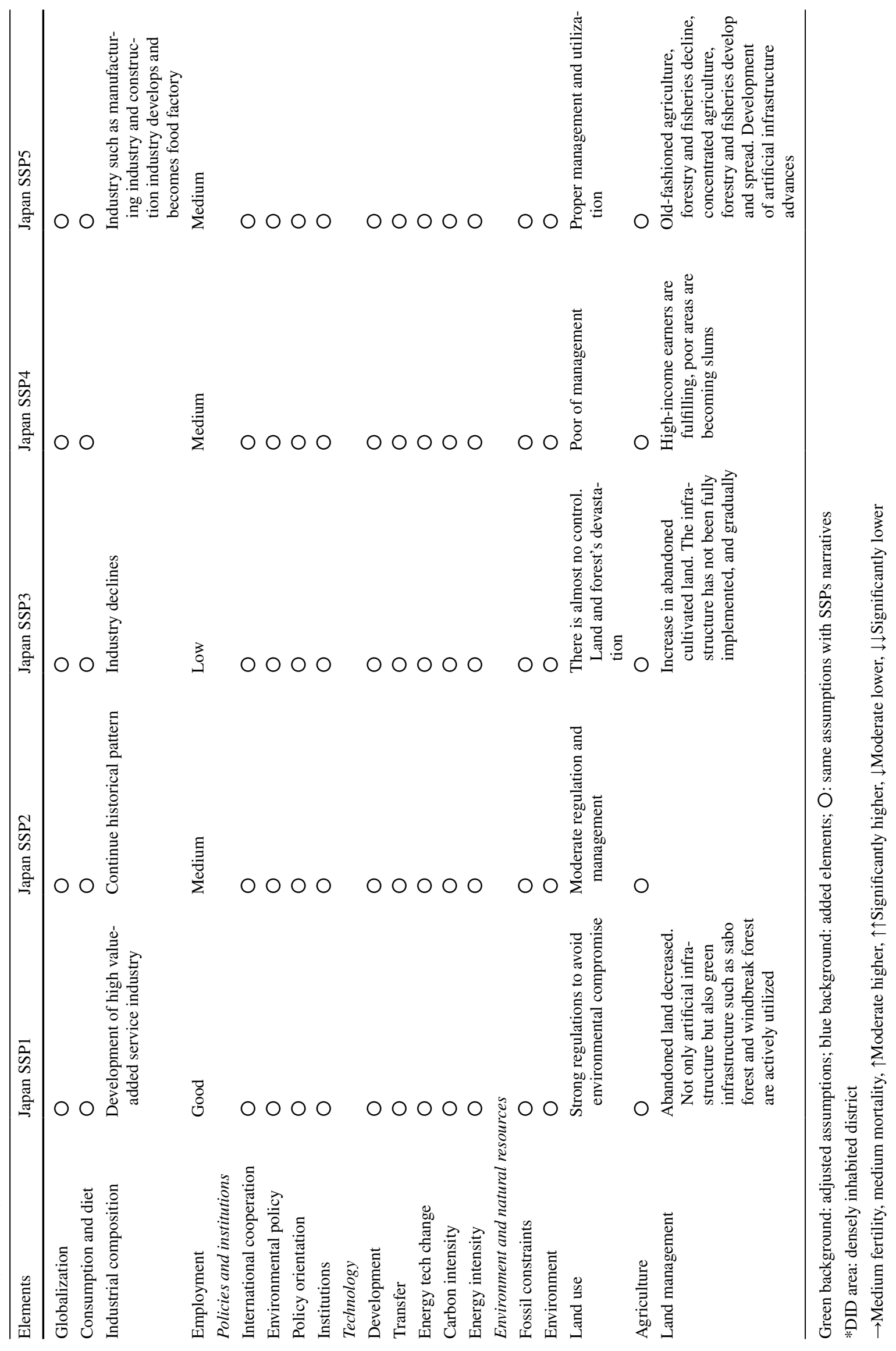


Table 4 Comparison of elements of Japan's demography between global SSPs (rich OECDs) and Japan SSPs

\begin{tabular}{lllll}
\hline Demographic & Total population & Fertility & Mortality & Migration \\
\hline SSP1 & Medium & Medium & Low & Medium \\
SSP2 & Medium & Medium & Medium & Medium \\
SSP3 & Low & Low & High & Low \\
SSP4 & Low & Low & Medium & Medium \\
SSP5 & High & High & Low & High \\
Japan SSP1 & Medium & High & Medium & Medium \\
Japan SSP2 & Medium & Medium & Medium & Medium \\
Japan SSP3 & Low & 1 & Medium & Medium \\
Japan SSP4 & Low & 1.2 & Medium & Medium \\
Japan SSP5 & High & Medium & Medium & Migration \\
& & & & 250 thou- \\
& & & & sand* \\
\hline
\end{tabular}

*Number of net migrants of non-Japanese origin is 250 thousand by 2035 , the rate of net migrants of non-Japanese origin assumed to be constant after 2036

The Japan SSP3 and Japan SSP4 were broadened using conditional estimates of low birth rates. The Japan SSP5 is a conditional estimate of 250,000 foreigners" migration in 2035 (however, only medium rates exist for birth rates and mortality rates). The movement of 500 thousand foreigners is too large compared to the global SSP5, and therefore we selected 250 thousand foreigners, which is closer to the population of global SSP5 in the year 2100. We also confirmed that these are within the scope of the discussion of the Japan SSPs' description. The results are presented in Fig. 3.
Projections of population by Japan SSP1-5 predict that the Japan population is likely to keep declining until 2100. Population curves of Japan SSP1 and Japan SSP2 are close, because the difference between high fertility and medium setting is not remarkable by NIPSSR.

Similar to global SSPs, Japan SSP3 has the lowest population, and Japan SSP5 has twice the population of Japan SSP3. The population of Japan SSP1-4 is about $20 \%$ less than SSP1-4; population of Japan SSP5 is about 25\% less than SSP5, compared to the year 2100. Compared with SSP3 and SSP5, the difference between Japan SSP3 and Japan SSP5 is smaller. In SSP5, the population is stable until 2050, which is difficult to apply to the declining birthrate and aging Japanese society. Japan SSP5 is fit by the national circumstances of Japan.

In addition, GDP of Japan SSPs is calculated by multiplying the per capita GDP of IIASA and the population of Japan SSPs. The results are shown in Fig. 4. Japan SSP3 has the lowest GDP, and Japan SSP5 has the highest DP. GDP is presented as real GDP measured in constant 2005 prices of purchasing power parity (PPP). GDP increases from US\$4064 billion in 2010 to US\$10646 billion in 2100 for Japan SSP5, and decreases to US\$2572 billion for SSP1. GDP of Japan SSP4 increases to US $\$ 4553$ billion in 2050 years, and then decreases to US\$3885 billion in 2100 years. GDP of Japan SSPs is about $20 \%$ less than SSPs, compared to the year 2100. The curve trends of Japan SSPs, GDP, and SSPs are similar.
Fig. 3 Comparing the total population size according to SSP1-5, SSP1'-5', Japan SSP1-5

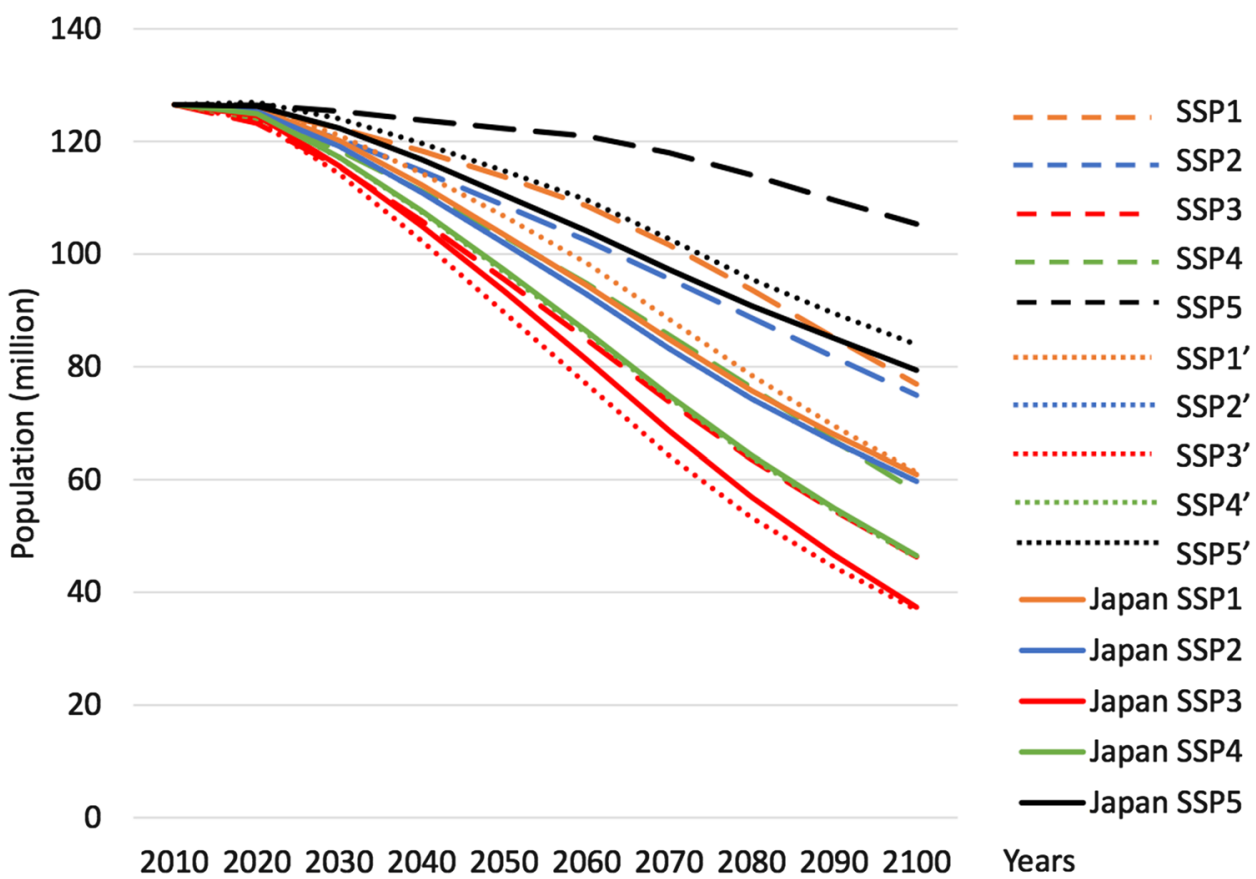


Fig. 4 Comparing the GDP according to the SSP1-5, Japan SSP1-5
16

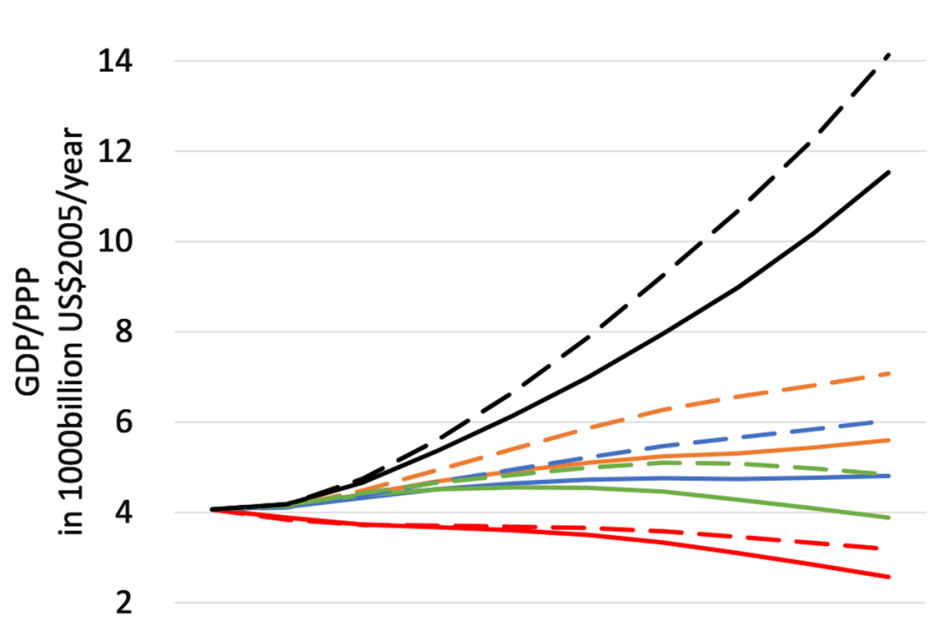

0

2010202020302040205020602070208020902100

_Japan SSP1

—Japan SSP2

—Japan SSP3

—Japan SSP4

—Japan SSP5

$-----\operatorname{SSP} 1$

$-----\operatorname{SSP} 2$

$-----\operatorname{SSP} 3$

----- SSP4

$-----\operatorname{SSP} 5$

years

\section{Discussion and conclusions}

This study provides a systematic methodology on how to establish downscaling SSPs, including qualitative and quantitative. This study not only describes Japanese SSPs in the global context but also provides a common methodology based on local use and development for governments and researchers, as well as a common data set for climate change mitigation and adaptation measures.

A procedure was proposed to correct the global SSPs' narratives, which summarized the elements and mapped SSP1-5. This procedure was a method of constructing a narrative scenario that corresponds to the global SSP and reflects the national and sub-national characteristics. Thus, we constructed a Japan scenario database that collected future scenarios of Japan and clarified the features that are not expressed in global SSPs. The quantification of scenarios is based on projections of population, education, urbanization, and GDP. This method can be used to establish country- and city-scale SSPs, by combining top-down and bottom-up approach, which will not deviate too much from the global SSPs, and also ensures certain regional characteristics. Providing both qualitative and quantitative sets can help further environmental assessment researches.

In the global SSPs, five different socioeconomic narrative scenarios (SSP1-5) are shown due to different challenges in mitigation and adaptation. Based on forecasts of the GDP, population, and education, urbanization quantification is made for each scenario (Crespo Cuaresma 2017; Dellink et al. 2017; Kc and Lutz 2017; Jiang and O'Neill 2017). Several attempts have been made to apply this to the scales of the national and sub-national (Absar and Preston 2015;
Nilsson et al. 2017; Palazzo et al. 2017;). However, it is possible to create a narrative through extensive discussions to determine the divers that influence the future through local participation. However, it is difficult to quantify the population or GDP to be used in the model analysis (Nilsson et al. 2017). Moreover, in the top-down studies (Absar and Preston 2015), the population and GDP shown in the global SPs are directly distributed to the domestic region, and it is not possible to express the characteristics of the country or the domestic region. Therefore, this study aims to quantify the elements by clarifying the unique characteristics of Japan and the factors affecting population and GDP in the national level.

In the workshop, participations examined the Japan SSPs requirements from the viewpoint of an integrated solution of various issues simultaneously with climate change adaptation. Thus, scenarios for regional population may be adopted as prefectural and municipal governments are strongly interested in the problem of population decline. However, it has been highlighted that it will increase the utilization possibility of Japan SSP1-5 in policy making, if there is one baseline scenario for reference regard for climate change adaptation. Nevertheless, we confirmed the importance of providing Japan SSP 1-5 for researchers who conduct impact assessment and the range of influences in Japan. In the key driver's voting process, it was pointed out that the scenarios differ depending on the development of industrial technology, the degree of dependence on foreign countries, the change in population and population distribution, the ability to respond, diversity, and disparities. In particular, additional descriptions include industry, employment, 
migration, responsiveness, and diversity as the main elements that influence the future of Japan.

This study did not establish a new population prediction model to obtain population data of Japan SSPs. It selected data sets from existing models that have been widely used by Japanese researchers and is also coherent to the narratives in Japan SSPs. Japan is a high-welfare and aging country, and the difference in the high, medium, and low mortality rates is not significant. The population prediction of global SSPs is generally higher than that of the existing population projections of Japan. These results make it impossible to use the definition of population directly. However, they make the necessary adjustments based on the population projections of SSPs to ensure that the population can meet both global SSPs and Japan's national conditions.

In the future, it is necessary to investigate variables and indicators that are highly relevant to the mitigation or adaptation assessments of each department and determine whether to quantify and consider quantitative methods of each element in Japan SSPs. Detailed information on the impact of climate change by region is important to effectively promote adaptation measures. Sub-national quantification will proceed if more complete information infrastructure can be developed. Based on more detailed information and data, it is expected to provide quantification information on basic variables and indicators (population, GDP, land use, etc.), widely used in impact assessment, and variables and indicators specific to sectors, such as agriculture, water resources, human health, etc., and contribute to adaptation policy. Furthermore, in addition to the detailed setting of the population, the economic activity and industry composition must be considered, and the economy and population considering the way of working and living of the residents must be estimated.

Funding This research was funded by the Environment Research and Technology Development Fund 2-1805 of the Environmental Restoration and Conservation Agency of Japan.

\section{Compliance with ethical standards}

Conflict of interest The authors declare that they have no conflict of interest.

Open Access This article is licensed under a Creative Commons Attribution 4.0 International License, which permits use, sharing, adaptation, distribution and reproduction in any medium or format, as long as you give appropriate credit to the original author(s) and the source, provide a link to the Creative Commons licence, and indicate if changes were made. The images or other third party material in this article are included in the article's Creative Commons licence, unless indicated otherwise in a credit line to the material. If material is not included in the article's Creative Commons licence and your intended use is not permitted by statutory regulation or exceeds the permitted use, you will need to obtain permission directly from the copyright holder. To view a copy of this licence, visit http://creativecommons.org/licenses/by/4.0/.

\section{References}

Absar SM, Preston BL (2015) Extending the shared socioeconomic pathways for sub-national impacts, adaptation, and vulnerability studies. Glob Environ Change 33:83-96. https://doi.org/10.1016/j. gloenvcha.2015.04.004

Alfieri L, Feyen L, Dottori F, Bianchi A (2015) Ensemble flood risk assessment in Europe under high end climate scenarios. Glob Environ Change 35:199-212. https://doi.org/10.1016/j.gloen vcha.2015.09.004

Calvin K, Bond-Lamberty B, Clarke L, Edmonds J, Eom J, Hartin C, Kim S, Kyle P, Moss R, McJeon H, Patel P, Smith S, Waldhoff S, Wise M (2017) SSP4: a world of inequality. Glob Environ Change 42:284-296. https://doi.org/10.1016/j.gloenvcha.2016.06.010

Carey C (2014) The CCAFS regional scenarios programme: external evaluation report on progress towards programme outcomes. CGIAR Research Program on Climate Change, Agriculture and Food Security (CCAFS), Copenhagen, Denmark

Carlsen H, Eriksson EA, Dreborg KH, Johansson B, Bodin Ö (2016) Systematic exploration of scenario spaces. Foresight 18(1):59-75. https://doi.org/10.1108/FS-02-2015-0011

Chaudhary A, Mooers AO (2018) Terrestrial vertebrate biodiversity loss under future global land use change scenarios. Sustainability 10(8):2764. https://doi.org/10.3390/su10082764

Crespo Cuaresma J (2017) Income projections for climate change research: a framework based on human capital dynamics. Glob Environ Change 42:226-236. https://doi.org/10.1016/j.gloen vcha.2015.02.012

Dellink R, Chateau J, Lanzi E, Magné B (2017) Long-term economic growth projections in the shared socioeconomic pathways. Glob Environ Change 42:200-214. https://doi.org/10.1016/j.gloen vcha.2015.06.004

Ebi KL, Hallegatte S, Kram T, Arnell NW, Carter TR, Edmonds J, Kriegler E, Mathur R, O’Neill BC, Riahi K, Winkler H, van Vuuren DP, Zwickel T (2014) A new scenario framework for climate change research: background, process, and future directions. Clim Chang 122:363-372. https://doi.org/10.1007/s1058 4-013-0912-3

Fricko O, Havlik P, Rogelj J, Riahi K, Klimont Z, Gusti M, Johnson N, Kolp P, Strubegger M, Valin H, Amann M, Ermolieva T, Forsell N, Herrero M, Heyes C, Kindermann G, Krey V, McCollum DL, Obersteiner M, Pachauri S, Rao S, Schmid E, Schoepp W (2017) SSP2: a middle-of-the-road scenario for the 21st century. Glob Environ Change 42:251-267

Fujimori S, Hasegawa T, Masui T, Takahashi K, Herran DS, Dai H, Hijioka Y, Kainuma M (2017) SSP3: AIM implementation of shared socioeconomic pathways. Glob Environ Change 42:268 283. https://doi.org/10.1016/j.gloenvcha.2016.06.009

IPCC (2000) Special report on emissions scenarios. In: Nakicenovic N, Swart R (eds) Cambridge University Press, Cambridge. https ://www.ipcc.ch/report/emissions-scenarios/

IPCC (2007) IPCC expert meeting report-towards new scenarios for analysis of emissions, climate change, impacts, and response strategies. Noordwijkerhout, The Netherlands. https://www.ipcc. $\mathrm{ch} /$ publication/ipcc-expert-meeting-report-towards-new-scena rios-for-analysis-of-emissions-climate-change-impacts-and-respo nse-strategies/

Jiang L, O'Neill BC (2017) Global urbanization projections for the shared socioeconomic pathways. Glob Environment Change 42:193-199. https://doi.org/10.1016/j.gloenvcha.2015.03.008 
Kc S, Lutz W (2017) The human core of the shared socioeconomic pathways: population scenarios by age, sex and level of education for all countries to 2100. Glob Environ Change 42:181-192. https ://doi.org/10.1016/j.gloenvcha.2014.06.004

Kim H, Rosa IMD, Alkemade R, Leadley P, Hurtt G, Popp A, van Vuuren DP, Anthoni P, Arneth A, Baisero D, Caton E, ChaplinKramer R, Chini L, De Palma A, Di Fulvio F, Di Marco M, Espinoza F, Ferrier S, Fujimori S, Gonzalez RE, Gueguen M, Guerra C, Harfoot M, Harwood TD, Hasegawa T, Haverd V, Havlík P, Hellweg S, Hill SLL, Hirata A, Hoskins AJ, Janse JH, Jetz W, Johnson JA, Krause A, Leclère D, Martins IS, Matsui T, Merow C, Obersteiner M, Ohashi H, Poulter B, Purvis A, Quesada B, Rondinini C, Schipper AM, Sharp R, Takahashi K, Thuiller W, Titeux N, Visconti P, Ware C, Wolf F, Pereira HM (2018) A protocol for an intercomparison of biodiversity and ecosystem services models using harmonized land-use and climate scenarios. Geosci Model Dev 11(11):4537-4562. https://doi.org/10.5194/ gmd-11-4537-2018

Kok MJT, Kok K, Peterson GD, Hill R, Agard J, Carpenter SR (2016) Biodiversity and ecosystem services require IPBES to take novel approach to scenarios. Sustain Sci 12(1):177-181

Kok K, Pedde S, Gramberger M, Harrison PA, Holman IP (2019) New European socio-economic scenarios for climate change research: operationalising concepts to extend the shared socio-economic pathways. Reg Environ Change 19(3):643-654. https://doi. org/10.1007/s10113-018-1400-0

König M, Loibl W, Haas W, Kranzl L (2015) Shared-socio-economic pathways. In: Steininger KW, König M, Bednar-Friedl B, Kranzl L, Loibl W, Prettenthaler F (eds) Economic evaluation of climate change impacts. Springer, Cham, pp 75-99. https://doi. org/10.1007/978-3-319-12457-5_6

Kriegler E, O’Neill BC, Hallegatte S, Kram T, Lempert R, Moss R, Wilbanks T (2012) The need for and use of socio-economic scenarios for climate change analysis: a new approach based on shared socio-economic pathways. Glob Environ Change 22:807822. https://doi.org/10.1016/j.gloenvcha.2012.05.005

Kriegler E, Bauer N, Popp A, Humpenöder F, Leimbach M, Strefler J, Baumstark L, Bodirsky B, Hilaire J, Klein D, Mouratiadou I, Weindl I, Bertram C, Dietrich JP, Luderer G, Pehl M, Pietzcker R, Piontek F, Lotze-Campen H, Biewald A, Bonsch M, Giannousakis A, Kreidenweis U, Müller C, Rolinski S, Schultes A, Schwanitz J, Stefanovic M, Calvin K, Emmerling E, Fujimori S, Edenhofer O (2017) Fossil-fueled development (SSP5): an energy and resource intensive scenario for the 21 st century. Glob Environ Change 42:297-315. https://doi.org/10.1016/j.gloenvcha.2016.05.015

Leimbach M, Kriegler E, Roming N, Schwanitz J (2017) Future growth patterns of world regions-a GDP scenario approach. Glob Environ Change 42:215-225. https://doi.org/10.1016/j.gloen vcha.2015.02.005

Nilsson AE, Bay-Larsen I, Carlsen H, van Oort B, Maiken B, Jylhä K, Klyuchnikovaf E, Masloboevf V, van der Watt L (2017) Towards extended shared socioeconomic pathways: a combined participatory bottom-up and top-down methodology with results from the Barents region. Glob Environ Change 45:124-132. https://doi. org/10.1016/j.gloenvcha.2017.06.001

NIPSSR (2017) Population Projections for Japan 2016-2065. National Institute of Population and Social Security Research, Tokyo. http://www.ipss.go.jp/pp-zenkoku/e/zenkoku_e2017/pp_zenko ku2017e.asp

O’Neill BC, Kriegler E, Riahl K, Ebi KL, Hallegatte S, Carter TR, Mathur R, van Vuuren DP (2014) A new scenario framework for climate change research: the concept of shared socioeconomic pathways. Clim Chang 122(3):387-400. https://doi.org/10.1007/ s10584-013-0905-2

O’Neill BC, Kriegler E, Ebi KL, Kemp-Benedict E, Riahi K, Rothman DS, van Ruijven BJ, van Vuuren DP, Birkmann J, Kok K, Levy M,
Solecki W (2017) The roads ahead: narratives for shared socioeconomic pathways describing world futures in the 21 st century. Glob Environ Change 42:169-180. https://doi.org/10.1016/j.gloen vcha.2015.01.004

Palazzo A, Vervoort JM, D’Croz DM, Rutting L, Havlíka P, Islam S, Bayala J, Kadi HK, Thornton P, Zougmore RB (2017) Linking regional stakeholder scenarios and shared socioeconomic pathways: quantified West African food and climate futures in a global context. Glob Environ Change 45:227-242. https://doi. org/10.1016/j.gloenvcha.2016.12.002

Pedde S, Kok K, Hölscher K, Frantzeskaki N, Holman I, Dunford R, Smith A, Jäger J (2019) Advancing the use of scenarios to understand society's capacity to achieve the 1.5 degree target. Glob Environ Change 56:75-85. https://doi.org/10.1016/j.gloen vcha.2019.03.010

Popp A, Calvin K, Fujimori S, Havlik P, Humpenöder F, Stehfest E, Bodirsky B, Dietrich JP, Doelmann J, Gusti M, Hasegawa T, Kyle P, Obersteiner M, Tabeau A, Takahashi K, Valin H, Waldhoff S, Weindl I, Wise M, Kriegler E, Lotze-Campen H, Fricko O, Riahi K, van Vuuren DP (2017) Land use futures in the shared socioeconomic pathways. Glob Environ Change 42:331-345. https:// doi.org/10.1016/j.gloenvcha.2016.10.002

Riahi K, van Vuuren DP, Kriegler E, Edmonds J, O’Neill B, Fujimori S, Bauer N, Calvin K, Dellink R, Fricko O, Lutz W, Popp A, Crespo Cuaresma J, Leimbach M, Kram T, Rao S, Emmerling J, Hasegawa T, Havlik P, Humpenöder F, Aleluia Da Silva L, Smith SJ, Stehfest E, Bosetti V, Eom J, Gernaat D, Masui T, Rogelj J, Strefler J, Drouet L, Krey V, Luderer G, Harmsen M, Takahashi K, Wise M, Baumstark L, Doelman J, Kainuma M, Klimont Z, Marangoni G, Moss R, Lotze-Campen H, Obersteiner M, Tabeau A, Tavoni M (2017) The Shared Socio-Economic Pathways and their energy, land use and greenhouse gas emissions implications: an overview. Glob Environ Change 42:153-168. https:// doi.org/10.1016/j.gloenvcha.2016.05.009

Rogelj J, Popp P, Calvin KV, Luderer G, Emmerling J, Gernaat D, Fujimori S, Strefler J, Hasegawa T, Marangoni G, Krey V, Kriegler E, Riahi K, van Vuuren DP, Doelman J, Drouet L, Edmonds J, Fricko O, Harmsen M, Havlík P, Humpenöder F, Stehfest E, Tavoni M (2018) Scenarios towards limiting global mean temperature increase below $1.5^{\circ} \mathrm{C}$. Nat Clim Change 8:325-332

SSP Data (2018) SSP public database version 2.0, International Institute for Applied Systerm Analysis. https://tntcat.iiasa.ac.at/SspDb $/$ dsd? Action $=$ htmlpage \&page $=$ about

Steininger KW, Bednar-Friedl B, Formayer H, König M (2016) Consistent economic cross-sectoral climate change impact scenario analysis: method and application to Austria. Clim Serv 1:39-52. https://doi.org/10.1016/j.cliser.2016.02.003

Taylor KE, Stouffer RJ, Meehl GA (2012) An overview of CMIP5 and the experiment design. Bull Am Meteorol Soc 93:485-498. https ://doi.org/10.1175/bams-d-11-00094.1

United Nations (2011): United nations, world population prospects: the 2010 revision, Department of Economic and Social Affairs, Population Division, New York

van Vuuren DP, Edmonds J, Kainuma M, Riahi K, Thomson A, Hibbard K, Hurtt GC, Kram T, Krey V, Lamarque JF, Masui T, Meinshausen M, Nakicenovic N, Smith SJ, Rose SK (2011) The representative concentration pathways: an overview. Clim Change 109(1):5-31. https://doi.org/10.1007/s10584-011-0148-z

van Vuuren DP, Stehfest E, Gernaat D, Doelman J, van Den Berg M, Harmsen M, de Boer HS, Bouwman AF, Daioglou V, Edelenbosch OY, Girod B, Kram T, Lassaletta L, Lucas P, van Meijl H, Müller C, van Ruijven B, van der Sluis S, Tabeau A (2017) Energy, land-use and greenhouse gas emissions trajectories under a green growth paradigm. Glob Environ Change 42:237-250. https://doi. org/10.1016/j.gloenvcha.2016.05.008 
Zandersen M, Hyytiäinen K, Meier M, Tomczak MT, Bauer B, Haapasaari PE, Olesen JE, Gustafsson BG, Refsgaard JC, Fridell E, Pihlainen S, Le Tissier MDA, Kosenius AK, Van Vuuren DP (2019) Shared socio-economic pathways extended for the Baltic Sea: exploringlong-term environmental problems. Reg Environ Change 19:1073-1086

Zhang D, Huanga Q, He Ch, Wu J (2017) Impacts of urban expansion on ecosystem services in the Beijing-Tianjin-Hebei urban agglomeration, China: a scenario analysis based on the shared socioeconomic pathways. Resour Conserv Recycl 125:115-130. https://doi.org/10.1016/j.resconrec.2017.06.003

Publisher's Note Springer Nature remains neutral with regard to jurisdictional claims in published maps and institutional affiliations. 